\title{
MUDANÇAS SOCIAIS E GÊNERO: VIVÊNCIAS DE ATUALIZAÇÃO DE MODELOS DE MASCULINIDADE EM DUAS COMUNIDADES DE PERNAMBUCO
}

\author{
Gender and social changes: experiences on \\ models of masculinities updates in two distinct \\ communities from Pernambuco State \\ Karla Galvão Adrião* \\ Pedro Nascimento**
}

\section{Resumo}

Este artigo reflete sobre a transformação social no cotidiano de homens, de duas comunidades de baixa renda distintas - uma na região metropolitana do Recife/PE, e a outra no litoral sul do estado. O objetivo é apresentar o diálogo entre duas pesquisas realizadas com homens adultos destas duas populações, marcados por experimentarem situações de mudanças sociais em suas formas tradicionais de vida: para os homens da primeira comunidade, a vivência do desemprego, e para os da segunda, a de um processo de implementação de novas tecnologias aliadas ao trabalho pesqueiro. O estudo basear-se-á na relação analítica entre gênero e atualização de modelos de masculinidades.

Palavras-chave: Gênero, transformação social, masculinidades.

* Mestre em Linguística pela Universidade Federal de Pernambuco e dutoranda do Programa de PósGraduação Interdisciplinar em Ciências Humanas - DICH/CFH da Universidade Federal de Santa Catarina. Pesquisadora dos núcleos NIGS e Margens - UFSC (kgalvaoadriao@hotmail.com)

** Mestre em Antropologia Social pela Universidade Federal de Pernambuco e Doutorando do Programa de Pós-Graduação em Antropologia Social - Universidade Federal do Rio Grande do Sul. Pesquisador do Núcleo Antropologia e Cidadania - NACI/UFRGS (pedrofgn@gmail.com) 


\section{Abstract}

This article reveals about the social change on men's daily life in two distinct low budget communities, one in Recife's metropolitan region and the other on the south coast of Pernambuco state. The main point is to present a dialogue between two researches made with adult men from this two communities, who have experienced social changes on their traditional forms of living: for the men in the first community, the fact of unemployment, and for those in the second, the process of implementing new technologies engaged on the fishing activities. The article is based on the analytic relation between gender and models of masculinities updates.

Key words: Gender, social changes, masculinities.

Este trabalho busca refletir sobre a transformação social no cotidiano de duas comunidades distintas, através da relação analítica entre gênero e atualização de modelos de masculinidades. O objetivo principal é o de apresentar alguns resultados de duas pesquisas realizadas com homens adultos de duas populações diferentes, porém marcadas por experimentarem situações de mudanças sociais em suas formas tradicionais de vida. Uma dessas populações é formada por homens residentes no bairro de Alberto Maia, município de Camaragibe, na região metropolitana do Recife-PE, uma comunidade de baixa renda. A outra é constituída por pescadores do litoral sul de Pernambuco, envolvidos em processo de implementação de novas tecnologias aliadas ao trabalho pesqueiro, a partir de um projeto de difusão tecnológica do governo do Estado (PEditec) ${ }^{1}$.

Dentre as várias questões que foram discutidas em cada população, trataremos aqui especificamente de explicitar qual o modelo de masculinidade partilhado (CONNELL, 1997; VALE DE ALMEIDA, 1995 e1996) por cada população e as estratégias utilizadas frente às mudanças vivenciadas

1 Importante reforçar que não estamos querendo forçar uma comparação entre dois grupos tão distintos e com peculiaridades próprias, tampouco colocar que os dois grupos enfrentam o mesmo tipo de questões; mas permitir a reflexão sobre dois contextos diferenciados. Sim, pois, apesar dessas diferenças, os dois grupos podem ser tomados como bons exemplos para permitir a reflexão e lançar questões sobre gênero, mudanças sociais; tomando o devido cuidado para não aprisioná-los em comparações 'forçadas'. 
por aqueles homens para se apresentarem como indivíduos que partilham deste modelo.

Para o desenvolvimento da investigação, utilizamos a observação participante e a realização de entrevistas com informantes-chaves ${ }^{2}$. Com relação à primeira comunidade, os informantes são moradores de uma área específica, conhecida como Invasão. Estes homens dos quais falaremos são os mais pobres da comunidade. Poucos têm trabalho regular, sendo que a grande maioria vive de biscates e um número significativo não trabalha. A opção por esta população punha em evidência as questões ligadas mais especificamente à dimensão do trabalho em suas vidas, muito embora, vários outros temas tenham sido postos em pauta.

$\mathrm{Na}$ segunda, os homens investigados são pescadores da colônia Z12 que se situa em Porto de Galinhas, abarcando também a comunidade de Serrambi, litoral sul de Pernambuco. Através da colônia foi firmada uma parceria com o então chamado 'Banco do Nordeste' e o governo do Estado na época da pesquisa, para implementação do Programa Estadual de difusão tecnológica (PEditec). Este tinha por objetivo trazer incrementos tecnológicos ao trabalho artesanal em todo o Estado, através de microprojetos específicos. Em nosso caso, optamos por trabalhar com o programa de pesca marítima, investigando como foco central a questão das mudanças provocadas pelo impacto tecnológico. Neste projeto, técnicos da Universidade Federal Rural de Pernambuco - UFRPE participaram, e tinham como meta transmitir o conhecimento sobre o uso dos aparelhos eletrônicos: rádio VHF, GPS (Global Position System - Sistema de Posicionamento por Satélite) e Ecossonda (sonda

2 Para o desenvolvimento das pesquisas em Camaragibe, Pedro Nascimento residiu durante três meses na comunidade no primeiro semestre de 1998 para o desenvolvimento de sua dissertação de mestrado em Antropologia Cultural/UFPE. Porém, desde 1997, desenvolve pesquisas nessa área, tendo, no ano de 1999, voltado a fixar residência na mesma comunidade para o desenvolvimento de uma nova pesquisa que fez parte do PRODIR III (terceiro programa de treinamento em pesquisa sobre direitos reprodutivos na América Latina e Caribe), promovido pela Fundação Carlos Chagas, com recursos da Fundação MacArthur. Karla Galvão fez visitas às comunidades entre os meses de dezembro de 1998 e setembro de 1999, onde realizou as entrevistas e fez observações diretas. Parte desses resultados fazem parte de sua dissertação de mestrado em lingüística, "No mar dos sentidos: linguagem, cognição e experiência no contexto da construção do conhecimento social”, defendida em 2000, na Universidade Federal de Pernambuco. 
para visualizar o 'fundo do mar') aos pescadores. Junto a esses equipamentos, os pescadores recebiam barcos de pesca mais possantes. Várias dimensões do mundo da pesca artesanal foram discutidas, porém interessa-nos aqui tarzer o debate sobre o universo do trabalho pesquisro, a introdução de novas tecnologias e os processos de atualização dos modelos de masculinidade.

\section{O GÊNERO, OS HOMENS E AS MASCULINIDADES.}

Para o desenvolvimento dessas pesquisas, procuramos explicitar quais eram os modelos de gênero segundo o qual homens e mulheres se orientavam em sua vida cotidiana. Esta forma de reflexão da masculinidade a partir do reconhecimento da existência de um modelo ideal ganhou força a partir de alguns autores que têm sido fundamentais para o avanço dos estudos nesse campo.

Os elementos destes modelos de masculinidade percebidos se coadunam basicamente com os estereótipos cristalizados culturalmente do "macho" (SAFFIOTI, 1987), para pensarmos em termos latinos, que são também, em nível mais geral, os valores mediterrâneos (PERISTIANY, 1971; BRANDES 1985). Tereza Valdes e Olavarria (1998, p. 14-15), referindose ao que é ser homem em Santiago do Chile, remetem à existência de um modelo semelhante, segundo o qual o homem tem autoridade, sobretudo no lar; é autônomo e livre frente a outros homens; tem força e coragem e não expressa suas emoções, tampouco chora; é o provedor do lar e é heterossexual. É possível pensar este modelo estendido a grande parte da América Latina, de acordo com os estudos de Norma Fuller (1998) no Peru, Mara Viveros (1998) na Colômbia, para citar alguns.

Para os objetivos deste trabalho não nos deteremos em apresentar detalhadamente como as características do modelo de masculinidade se apresentam para a população como um todo. $\mathrm{O}$ importante a ser considerado é que esta referência geral está presente na maioria dos homens. Isto não quer dizer, em absoluto, que todos eles se apresentam da mesma forma, mas referese à forma que temos utilizado para pensar sua presença através da noção de atualização. Chamamos de atualização o fato de que, mesmo quando os homens estão questionando ou criticando determinados elementos da masculinidade, é 
a esse modelo geral que eles estão se referindo, ao mesmo tempo em que sua vida cotidiana é marcada pela variação, ruptura, descontinuidade, etc.

As questões que nos foram colocadas e que viabilizaram esta investigação remetem a questionamentos mais gerais, que têm orientado as discussões em nível acadêmico e político nas últimas décadas no que se refere aos avanços dos estudos de gênero. No entanto, a problematização desses níveis implica em muitas do que apenas reafirmar que o gênero se constitui numa construção histórica e culturalmente datada. Não que isto seja uma questão menor. Suas implicações são fundamentais para que seja possível avançar, e muitos autores já se propuseram a traçar seu histórico sob vários prismas (BARBIERI, 1991; HEILBORN, 1992; SCOTT, 1993; VALE DE ALMEIDA, 1995; CORREAA, 1996; FONSECA, 1996, para citar apenas alguns).

Referimo-nos à necessidade de incorporarmos a percepção de que, por ser constituído dessa forma, o gênero ultrapassa os sujeitos específicos que orienta e, para ser satisfatoriamente utilizado teoricamente, precisa romper com a associação inequívoca entre o masculino e o feminino e os sujeitos associados a um ou a outro. Nossa reflexão se apresenta como mais uma contribuição a este processo, mas ao mesmo ao e perde na noção de que o estudo sobre os homens prescinde do que se construiu ao longo desses anos de estudos sobre as mulheres e depois sobre o gênero (FONSECA, 1996). Pretendemos, assim, contribuir aos estudos de gênero na sua busca de superar a reificação no feminino (LEAL \& BOFF, 1996). Para isto, partilhamos de alguns postulados de autores como Connell (1987 e 1997) em seu chamado à percepção de que não existe uma só masculinidade, mas sim, uma masculinidade hegemônica, que seria a masculinidade padrão, considerada normal e esperada/idealizada nas sociedades ocidentais; e que seria 'branca, heterossexual e dominante'. Acompanhemos as palavras do autor:

Em vez de tentarmos definir a masculinidade como um objeto (um caráter de tipo natural, uma conduta-padrão, uma norma), necessitamos nos centrar nos processos e relações por meio dos quais homens e mulheres levam vidas envolvidas 
no gênero. A masculinidade (...) é ao mesmo tempo a posição nas relações de gênero, as práticas pelas quais os homens e as mulheres se comprometem com essa posição de gênero, e os efeitos destas práticas na experiência corporal, na personalidade e na cultura (CONNELL, 1997, p. 35) ${ }^{3}$.

Esta formulação se afina com um outro passo, igualmente importante, que precisa ser dado, no sentido de considerar o gênero não como sendo apenas o estudo das relações entre homens e mulheres, mas inseri-lo numa perspectiva semelhante à de Marilyn Strathern (apud VALE DE ALMEIDA, 1995, p. 129), segundo a qual gênero "são as categorizações de pessoas, artefatos, eventos, seqüências etc., que se baseiam numa imagética sexual, nos modos como o caráter distintivo das características macho e fêmea concretizam as idéias das pessoas acerca da natureza das relações sociais".

Deste modo, os significados relacionados ao gênero, acabam por se constituir numa dicotomia fundamental e princípio classificatório a partir de uma simbólica de divisão do mundo em masculino e feminino (VALE DE ALMEIDA, 1996), a qual foi ricamente sistematizado por Bourdieu (1995). O padrão geral da masculinidade seria a masculinidade hegemônica, a partir da qual - sendo buscada, questionada ou negada - as outras possibilidades de exercício da masculinidade, se constituiriam: "a masculinidade hegemônica é um modelo ideal que, não sendo atingível (...) por nenhum homem, exerce sobre todos os homens e sobre as mulheres um efeito controlador (VALE DE ALMEIDA, idem, p. 163).

Com relação à questão do trabalho na definição da identidade masculina, será importante a noção defendida por Cinthya Sarti (1996, p. 66) para quem "o trabalho é muito mais do que o instrumento da sobrevivência material, mas constitui o substrato da identidade masculina, forjando um jeito de ser homem. É condição de sua autonomia moral, ou seja, da afirmação positiva de si, que lhe permite dizer: eu sou”. Disto decorre a importância de remeter os dispositivos de formação da masculinidade que

3 Tradução livre. 
estamos investigando à discussão sobre honra, enquanto direito ao orgulho de si mesmo, como bem definiu Pitt-Rivers (1971, pg. 13), associando-a também à pobreza, onde a honra vincula-se à virtude moral e não à posição social (SARTI, idem, p. 119).

Sobre os processos tecnológicos e sua relação com a constituição das subjetividades, relacionamos neste trabalho a interface entre o mundo do trabalho, sua importância para a conformação das masculinidades, e a relação com novos significados atrelados a este espaço intersubjetivo. Busca-se avaliar o impacto de novas tecnologias na construção do conhecimento dos indivíduos, ou seja, como estes reconstroem o impacto de novos significados introduzidos ao mundo do trabalho. Consideramos que a recepção dos novos artefatos tecnológicos não se dá de forma passiva. Ela implica reelaborações, incorporações e resistências dos grupos sociais dentro dos quais essas transformações atuam. São construções que se baseiam em referenciações sóciolingüísticas, onde processos de introdução de novos signos são acoplados, em espaços de ancoragem a antigos significados (MONDADA, 1994).

Tendo estes elementos como orientação de nossa análise, apresentaremos as características das comunidades investigadas e alguns resultados a que chegamos.

\section{MASCULINIDADE E POBREZA EM CAMARAGIBE}

A população de Camaragibe que foi estudada pertence a uma área conhecida como "invasão". Esta corresponde a uma área com cerca de 1500 famílias, ocupada nas últimas duas décadas e formada atualmente, como grande parte da população do bairro, por famílias oriundas do interior do Estado, de antigas zonas canavieiras e de demais partes da região Metropolitana do Recife (RMR). Pensando a Invasão como uma área geográfica específica, ela própria é configurada de modo diverso por seus habitantes. Enquanto que para os moradores de outras áreas ela é percebida como um todo negativo, às vezes chamado de "a favela" e apontada como o lugar mais violento do bairro, onde se concentram os "maconheiros" e 


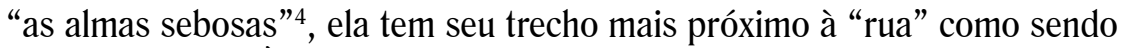
mais valorizado. À medida que se vai afastando, em direção ao seu final e se aproximando do trecho de mata atlântica ainda restante, é considerado mais violento e, assim, menos valorizado.

No que diz respeito ao trabalho, muitos homens encontram-se desempregados. Não apenas no sentido de enfrentar a intermitência do mercado, mas por estarem identificados por períodos longos sem trabalharem (de um a sete anos ou mais) e muitos deles não procurarem biscates para fazerem, adequandose à condição de "sustentados por" alguém, ou seja, a esposa, a mãe ou irmãos.

Apesar da diversidade de experiências, é possível identificar uma referência geral ao que consideram ser homem. Referência para os valores, os comportamentos, os sentimentos, as posturas que devem servir de orientação para estes homens. Por outro lado, será possível, quando observado o cotidiano desses homens, perceber que "a forma culturalmente exaltada de masculinidade só corresponde às características de um pequeno número de homens" (VALE DE ALMEIDA, 1995, p. 150).

Segundo o modelo hegemônico de masculinidade apresentado, além de ter uma esposa e uma casa, emancipando-se dos pais, um homem só se realiza completamente quando é também pai, mesmo que isso não seja planejado na maioria das vezes (SCOTT, 1990, p. 45). Ainda de acordo com este modelo, o homem é o provedor "de teto, alimento e respeito" (SARTI, 1996, p. 38). As expressões "não deixar faltar as coisas em casa”, "cumprir com as obrigações", "dar conta das coisas da casa" surgem em suas falas de modo extremamente recorrente. Há uma relação direta entre ser homem e ser capaz de suprir as necessidades materiais da família. O homem deve ser capaz de dar tudo que a família precisa sem que a mulher trabalhe fora de casa. Quando a possibilidade de trabalho feminino extradoméstico é considerada, sempre é pensada como um complemento, quando o rendimento do homem não é suficiente.

O trabalho feminino fora do lar ao ser, a princípio, negado e, depois, apontado como um recurso de segunda ordem, um complemento ao trabalho masculino, informa acerca das expectativas que estes homens têm das mulheres

4 Maconheiro é o termo utilizado para traficantes usuários de drogas, bem como para delinqüentes em geral. Alma sebosa também é usado nesse mesmo sentido, porém não remete necessariamente às drogas. 
enquanto donas de casa, mas remete também a uma referência mais geral, em que as mulheres se inserem, qual seja a de que as mulheres são potencialmente infiéis e o trabalho extradoméstico acentuaria essa expectativa.

Ao mesmo tempo em que consideram a possibilidade de traição, sua compreensão de homem enquanto "controlador" da mulher impele à crença de que é possível impedir sua concretização. Este seria mais um desafio. Manter sob controle os impulsos femininos de traição. Por outro lado, este temor pode ser pensado também como não sendo apenas resultado da infidelidade feminina, mas a percepção de que o homem - todos os homens - não tem controle sobre a sexualidade, tem muitas relações sexuais e necessariamente com mulheres diferentes e duvidam de que "exista um homem que não tenha tido uma mulher fora”.

Existe o hábito de divulgar-se para todos os amigos as mulheres que arranjam fora. Estas descrições sempre beiram os limites da realidade, configurando-se em "torneios de virilidade" (NASCIMENTO, 1995, p. 50; ver também VALE DE ALMEIDA, 1995, p. 187), verdadeiras disputas nas quais está em questão apresentar-se como o que teve o maior número de relações numa só noite, o que tem o maior número de mulheres, além de serem estas tidas como as mais maravilhosas. E assim está indiretamente posta a idéia do homem como provedor mais uma vez, tanto de pão quanto de respeito, pois o fato de a mulher trair é pensado enquanto decorrência de o homem não "cumprir com suas obrigações" - todas elas.

Certa vez ouvimos um homem provocar um colega na rua: "mulher com fome bota chifre. E com menino, pior ainda”. E depois comentar com um outro que estava a seu lado: "a minha não bota porque tudo que eu ganho é pra dentro de casa. Ela pode botar chifre, mas é de barriga cheia”. O problema para o homem ter mais de uma mulher não estaria nunca dado pelas mesmas questões que a mulher. Quando se censura um homem por ter outra mulher ou outra família, esta crítica é referida ao fato de ele ter condições de prover satisfatoriamente os dois lares. Se um segundo lar leva-o a "faltar com as coisas em casa”, este será desaprovado, mas se é capaz de sustentar os dois, isto pode ser visto como um elemento a mais na definição do ser homem. Ele pode mostrar aos demais que é "tão homem” que pode sustentar mais do que uma mulher. 
O único medo admitido direta ou indiretamente é o de ser traído. Tão certo quanto o fato de que o homem pode e deve ter várias mulheres, é o temor que, embora referido aos outros, não é menos presente, que a mulher traia, posto que isto não é dado pelo homem, mas seria constituinte da "índole feminina". Ao homem caberia sempre buscar minimizar os riscos deste evento apenas em relação a sua esposa/companheira/namorada, pois é o domínio que o ameaçaria. Das mulheres que, segundo seu julgamento, não são 'sérias' já se espera que traiam. Mesmo em caso de ser traído pela esposa, este não é um fato que de todo desonre. Dependerá do tipo de atitude que se tome frente ao fato. Neste caso, o controle pode retornar às mãos do homem. Se for traído e separar-se da esposa, ainda assim. Às vezes, procura-se construir a noção de que a traição feminina não traz mesmo nenhum 'prejuízo' ao homem em termos morais, desde que se tome esta decisão acertada frente ao caso.

O grande problema parece estar naqueles que, sabendo-se traídos, mantém a relação ou, então, nos que se separam e depois 'aceitam'a mulher de volta. São os chamados "cornos mansos”, a pior coisa que um homem pode ser, ou seja, a situação que denota perda total de controle sobre a mulher (SCOTT, 1990, p. 41), a perda da autonomia.

A despeito da existência desta masculinidade hegemônica, constituemse no dia a dia situações que demonstram a existência de distintas formas de vivência das masculinidades, isto é, outras masculinidades que não se acoplem ao conceito de uma hegemonia de constituição. É importante pontuar novamente que a masculinidade hegemônica é um modelo cultural ideal que exerce sobre todos os homens e sobre as mulheres um efeito controlador, mas ao mesmo tempo não é "atingível - na prática e de forma consciente e inalterada - por nenhum homem" (VALE DE ALMEIDA, 1996, p. 163).

Muitos dos homens que percebiam a função de provedor do lar como a mais importante de um homem não tinham condições de cumprila totalmente às vezes, nem parcialmente, outras. Trabalhando fora, suas esposas muitas vezes ganham mais que eles e afirmam estas que, quando começam a ganhar algum dinheiro, alguns dos maridos deixam de trabalhar e esperam pelo seu dinheiro. Além desta 'divisão', nem sempre igualitária, 
do orçamento doméstico, devido ao grande número de desempregados, muitos lares são sustentados pelas esposas, mães ou outro parente. Embora muitos vivam de biscates, outros já não o fazem, nem procuram emprego, mas isto não implicou num redimensionamento das atividades domésticas. Um deles, sem trabalhar já há mais de cinco anos, afirmou que sua esposa sai de casa para trabalhar às cinco horas da manhã e deixa a sua comida já pronta, enquanto ele fica os dias entre os bares e a TV. Em outro momento, radicaliza esta situação, usando um recurso diferente quando a força não funciona. Certa vez, sua esposa reclamou em um bar porque seu proprietário tinha vendido fiado a seu marido sem sua autorização. Depois que ela se foi, disse malandramente; "tá botando bocão por que? Não é pra me sustentar que ela trabalha?".

Mas nem todos falam nem sentem da mesma maneira. O "botar bocão" não é sempre passível de ser ironizado. Um destes homens desempregados afirmava: "o que eu não gosto é que ela fica querendo botar bocão, mandar em mim". Um outro, também desempregado, falava do mesmo incômodo e da impotência frente à situação: "eu acho que mulher quando trabalha fora passa a querer dominar o homem. A minha, quando trabalhava, chegava em casa, tava as coisas feitas, os meninos tomado banho... Aí eu tinha tomado uma dose... ela vinha me dar um beijo e dizia: tu tava bebendo... e ficava querendo me controlar".

Controle sobre as próprias vontades, um imperativo da masculinidade, já não pode ser atualizado por muitos. O próprio casamento, ou o fato de poder anunciar aos amigos que têm uma mulher depende de outras circunstâncias. Um dos informantes, vivendo sozinho e sobrevivendo de biscates falou, referindo-se a uma namorada que diz ter em um loteamento vizinho a Alberto Maia: "ela quer morar comigo, mas eu não levo ela pra casa porque sozinho eu já passo fome, imagina com uma mulher?!".

Frente à infidelidade feminina, como vimos, a atitude mais coerente do homem é abandonar a esposa. Ser traído só é um mal maior do que o fato de não tomar esta atitude ao saber-se assim. São os "cornos mansos" que são vistos com perplexidade por alguns: "eu conheço um cara que mora aqui perto que todo mundo sabe que a mulher deixou ele para morar com outro cara e passou uns tempos vivendo com ele e até arrumou um 
filho dele. Quando ele deixou ela, ela voltou pro marido. Ele aceitou ela e ainda ta criando o menino". É por esta razão que, mesmo que a ex-mulher queira voltar, eles dizem só aceitariam se pudessem ir morar em outro local, pois continuando a morar em Alberto Maia, aconteceria o mesmo que aconteceu a um outro amigo, que muitas vezes serve de motivo de risos para os demais, seja por sua constante embriaguez, seja porque quando está embriagado, traz à tona o segredo que a todo custo ele tenta esconder: o fato de ser casado com a mesma mulher que já o abandonou e morou com outro no mesmo bairro por mais de um ano, tendo depois voltado pra ele.

Frente à impossibilidade de vivenciarem em seu cotidiano várias características do modelo, os homens se utilizam de diferentes estratégias para atualizarem o mesmo em suas vidas. Os bares aparecem como espaço privilegiado para a definição e a atualização de um certo modelo de masculinidade. Por sua característica de informalidade, ele comporta elementos que problematizam algumas das características mais marcantes da masculinidade hegemônica ao permitir aos homens a emersão dos sentimentos e a visualização de suas fragilidades, em grande medida, favorecidas pelo consumo do álcool. Do mesmo modo, o fato de colocar homens distintos, sob vários pontos de vista, segregados das mulheres em um mesmo espaço, faz com que se visualize as assimetrias internas às masculinidades. Não é apenas em relação a este outro ausente - a mulher - que o homem se diferencia e identifica, mas entre os próprios homens há códigos que definem o que é ser mais ou menos homem (VALE DE ALMEIDA, 1996, p. 163). Pensamos os bares enquanto palco por entendermos que os homens encontram aí um espaço para o aprendizado das masculinidades, as quais se constituem num processo social frágil, autovigiado e disputado (VALE DE ALMEIDA, idem; LEAL \& BOFF, 1996). Nele se delimitam que conversas, posturas e atitudes podem informar sobre o que é ser homem, bem como manter-se assim (NASCIMENTO, 1995).

Imaginar os bares como espaços estratégicos à elaboração de imagens de masculinidades, talvez pareça simples já que se pode pensá-los como espaços propícios a isto, devido a sua informalidade. $\mathrm{O}$ bar permitiria uma redefinição de certos valores em que a esperteza e o domínio de uma certa 
retórica já contribuiria para, de algum modo, reinstalar uma masculinidade sempre ameaçada a ser reposta (LEAL \& BOFF, idem). Mas como pensar a realização deste feito em outros contextos, aparentemente mais austeros e rigorosos, onde a incapacidade de cumprir as demandas é mais diretamente cobrada e imputada como falha?

Vejamos como essas questões estão presentes no contexto dos arranjos familiares que se formam em casos de impossibilidade de provimento do lar pelos homens. Mesmo sendo inegável a existência de um débito considerado tanto pelos próprios homens, quanto pelos demais, quando esta tarefa não é cumprida, é possível ver que, ainda assim, são construídas estratégias de reversão deste contexto, fazendo-se emergir sentidos diversos. Aqui entram a figura da mãe transferindo autonomia ao filho; uma redefinição do tempo, em que a atual situação é vista como uma fase; até os casos em que o infortúnio assume sentido de vantagem. São os casos em que os homens passam a tirar proveito do trabalho feminino, configurando sua situação de despossuído como esperteza. Por fim, todas estas elaborações são perpassadas por uma tentativa insistente de construção de imagens positivas através dos mais diversos tipos de discursos. A elaboração de um elogio de si dá-se, seja através da idealização do passado, remetendo ao que são considerados grandes feitos na esfera sexual, afetiva ou conjugal e profissional; a associação de sua imagem a "pessoas de bem", amigos e pessoas ricas. Consideramos que nesta atividade, um dos principais recursos é a criação de uma estrutura, na qual se constrói um panteon de outros marginalizados com os quais se identificarão de modo contrastivo: mesmo nas situações em que se está muito distanciado das "recomendações" do modelo central da masculinidade, ainda é possível considerar-se hierarquicamente acima das mulheres, dos homossexuais, dos ladrões e dos "maconheiros".

A princípio, estas questões nos chegaram de modo reticente. Perguntado se estava trabalhando, e como era mantida financeiramente a casa, um de nossos informantes afirmou que era ele e sua esposa: "ela bota pra dentro e eu também”. Imaginamos que fosse aposentado ou recebesse alguma pensão. Na seqüência, ele começou a esclarecer: "Minha mãe me dá. Minha mãe banca eu e meu irmão”. Só assim foi possível entender que sua mãe era empregada 
doméstica e dizer que também "bota dinheiro pra dentro" de casa, significava um recurso onde este homem buscava alguma autonomia através da mãe. Numa acrobacia lingüística, na qual o jogo das relações de parentesco fazia mãe e filho aproximarem-se e quase serem uma só coisa em oposição à estrangeira esposa (ver FONSECA, 1987). Este homem se via, ao menos naquele momento, desobrigado de dizer que era "sustentado pela mulher".

Quando recursos desta natureza não são utilizados, a afirmação de que, além de não estar trabalhando, é a esposa quem está sendo responsável pelo sustento da casa, não é feita de forma direta. Uma das justificativas mais comuns é a de se apresentar o contexto atual de desemprego como algo temporário: "esses dias eu tô parado..." ou "o negócio não ta muito bom, quem tá sustentando a casa é a mulher... quando eu não tenho, ela é quem sustenta”. Quando não é esta fala de um tempo modificado (que na maioria das vezes, significa muito tempo), mas seguindo a mesma lógica, muitos apresentam um discurso "moderno", sinalizando naturalidade para sua posição de dependência: "mas ela sabe que comigo é nenhuma" ; quando eu não tenho, ela tem...”. Frente ao modo de confrontar-se com a realidade, em que não é possível agir de modo compatível com as prerrogativas do modelo, é preferível antes se admitir incapaz, reelaborar o próprio modelo. É sempre possível dar novos sentidos à realidade vivida. É possível contar com um futuro em que haverá possibilidade de estabelecer a ordem perdida. E aqui falamos de um estabelecimento que não é necessariamente o de um tempo vivido. Não importa, ao menos neste caso, perceber se será ou não alcançado este tempo; se o tempo em que "eu não tô podendo", vai deixar de existir. O mais importante é perceber este redimensionamento do tempo, remetendo-se a um futuro, como uma possibilidade de se conviver com um presente que não é o idealizado ou desejado.

Estas questões remetem ao que havíamos pontuado como sendo os recursos usados quando não se pode vivenciar as prerrogativas do modelo. Nesta população específica, há o fato marcante de muitos homens estarem enfrentando a impossibilidade de serem os provedores de seu lar.

5 Expressão muito utilizada que equivale a "não tem problema”, "não tem frescura” ou "deixa pra lá”, indicando sentido de normalidade. 
Para os pescadores do litoral sul de Pernambuco, as características são bastante diferenciadas em alguns aspectos, e não queremos aprisioná-los às mesmas interpretações. Para além disso, o fato de estes homens estarem também passando por reconfigurações na forma como se relacionam com 0 trabalho numa interface com a aquisição de novas tecnologias, nos remete a um exercício que pode ser frutífero: como esses homens lidam com a perspectiva de virem a mudar nesses aspectos. Algumas semelhanças, para nós, parecerão interessantes.

\section{OS PESCADORES, O TRABALHO, A AQUISIÇÃO DE NOVAS TECNOLOGIAS E AS MASCULINIDADES: NOS LIMITES DO MAR}

O mar é aquele conhecido por eles. Local de trabalho, lócus de encontros e de construção de relações cotidianas. Um mundo constrói-se: em que 0 ofício de pescador e o próprio ato de constituir-se enquanto homem faz parte do cenário. O cenário é a praia e o mar, a colônia/associação de pescadores e a família, os amigos e o lazer, o trabalho e a pesca. Neste tópico de nosso trabalho traremos um pouco do relato dos pescadores sobre o universo da pesca e as relações constituídas neste espaço. Além disso, traremos o relato da introdução dos novos aparatos tecnológicos e sua introdução no mundo do trabalho. Enquanto para os homens apresentados acima, o desafio é posto por uma conjuntura em mudança na qual é cada vez mais difícil um trabalho que os coloque na condição de provedores de seus lares, as mudanças ocorridas no universo dos pescadores serão descritas pensando-se na inter-relação entre a constituição de um modelo de masculinidade que busca ser atualizado a partir da vivência no mundo do trabalho sob fortes mudanças.

Todos os pescadores entrevistados são casados, chefes de família e provedores do lar. Todos eles possuem barcos possantes e equipamentos eletrônicos vindos no pacote tecnológico do projeto PEditec, ao qual aderiram, através da associação de pescadores das comunidades na cidade de Ipojuca, litoral sul de Pernambuco. Antes da difusão tecnológica, estes pescadores aprenderam o ofício através do contato com outros pescadores mais velhos, na prática da pescaria. Ser pescador não é, segundo eles, algo 
a que qualquer homem tenha acesso. Aqueles que conseguem superar os medos do mar em dias de chuva ou tempestade e que não enjoam mais com o balanço das ondas podem começar a iniciar-se. "Para ser pescador é preciso inteligência, saber se orientar no mar, saber os 'cabeços' e 'pesqueiros' que existem, os tipos de peixes, o tipo de solo...”.

\section{O MUNDO DOS PESCADORES: TRABALHO NO MAR}

Os pescadores das comunidades investigadas vivem da pesca artesanal. Isto significa dizer que a pesca é realizada através de tecnologia diversa da que foi introduzida com o projeto PEditec, e o conhecimento do mar é adquirido através da prática concreta da pesca diária acompanhada de outros pescadores mais experientes. A vida em comunidade tem características próprias das colônias de pescadores dos mares pernambucanos em geral. As famílias vivem em torno do trabalho pesqueiro e os filhos ajudam seus pais até a adolescência, quando decidem se querem seguir o ofício de pescador ou não. Muitos não optam pela vida de pescador, que é apontada pelos próprios pais como uma vida muito difícil e sem perspectivas.

As esposas auxiliam na manutenção e venda do pescado, quando ele é trazido do mar. Mulher no mar só encontramos quando realizando pescas ditas inferiores e que não necessitam de força. São as catadoras de mariscos dos mares do litoral norte. Nas duas comunidades estudadas, que localizam-se no litoral sul do Estado, não encontramos essa prática pesqueira, e, por conseguinte, as mulheres trabalham apenas auxiliando os maridos no armazenamento, trato e venda do pescado. $\mathrm{O}$ mundo da pesca não é permitido às mulheres, a não ser em funções exercidas em terra. Ao mar só vão os homens. Em algumas comunidades, mulheres chegam a quebrar esse modelo, entretanto, nas comunidades por nós estudadas as mulheres participavam da pescaria tomando conta da colônia na ausência dos homens, tratando os peixes e comercializando-os.

As famílias vivem em torno da pesca, pois os homens vão ao mar, suas esposas trabalham em terra nos afazeres relacionados à pesca (inclusive fazendo a alimentação que será levada em alto-mar); os filhos podem estar aprendendo o ofício de pescador, trabalhando ou estudando, 
como já mencionado; e as filhas, em sua maioria, ajudam as mães no trato do pescado e demais atividades relacionadas.

As famílias dos pescadores montam seus trabalhos de venda, trato e captura do pescado, organizados em torno da colônia de pescadores que é, em alguns casos, a extensão de suas casas. Há apenas uma colônia que trata dos interesses dos pescadores de ambas comunidades. A colônia situa-se no vilarejo maior e os pescadores do outro vilarejo precisam deslocar-se em torno de $10 \mathrm{~km}$ até ela. As duas comunidades assemelham-se em organização do trabalho pesqueiro e na forma de lidar comunitariamente com o ofício de pescador. Ou seja, possuem representações bastante aproximadas com relação ao que é o trabalho pesqueiro e como este pode e deve ser desempenhado. Podemos dizer inclusive, que apesar das peculiaridades locais, as comunidades de pescadores do litoral pernambucano como um todo se aproximam e assemelham-se bastante na forma de lidar com o trabalho pesqueiro. Portanto, para efeito de análise, trataremos as duas comunidades escolhidas como uma 'grande comunidade', visto que as semelhanças entre elas são bem maiores que as particularidades; entretanto, sem deixar de frisar as possíveis particularidades quando se fizer necessário.

Os pescadores embarcavam rumo ao mar por um a dois dias apenas. Com a chegada dos novos barcos, com motores mais possantes e reservatório de gelo maior, eles passaram a embarcar nas segundas-feiras, retornando às vilas de Porto e Serrambi no final da semana, quando retiram o peixe para ser comercializado. Alguns, entretanto, continuam passando poucos dias no mar, a depender do tipo de pesca a se realizar e da quantidade de peixe que conseguem pescar.

Para os pescadores, o mar é um deserto com algumas ilhas que são denominadas de 'cabeços'. Nesses locais específicos, a fauna marítima instalase e há vida. Os peixes vão a estes locais, ou moram mesmo neles, pois lá há alimentos. Os pescadores contam que sabem a localização destes cabeços porque eles já foram descobertos por outros pescadores anteriormente, sendo a informação passada de geração em geração. Para marcar os cabeços na memória e não perder esses mapas marítimos de localização dos cardumes, os pescadores utilizam-se de orientações que eles chamam de 'marcações'. 
Essas marcações são feitas de acordo com um ponto fixo na terra visto do mar, e de mais um ponto que vai mudar à medida que o barco navega. Esses dois pontos são marcados e cruzam-se no momento em que o barco encontrase no lugar certo para a pesca, ou seja, em um determinado 'cabeço'. Aos cabeços e às marcações dos mesmos, os pescadores dão nomes específicos que são conhecidos por todos. São como locais fixos onde há certos tipos de peixes e onde se deve, portanto, pescar. Os cabeços podem ser formados por diferentes tipos de solo. De acordo com o tipo de solo - calcáreo, arenoso, pedregoso, etc - os pescadores identificam as espécies de peixes que podem ser encontradas. A profundidade do cabeço também dá muitos indícios de que tipo de pesca pode ser ali praticado: quais instrumentos necessários, se há possibilidade de se pescar no local com os apetrechos (linha, anzol, rede etc.) disponíveis no momento e os tipos de peixe. Também há alguns cardumes itinerantes que podem ser encontrados entre um cabeço e outro, nos espaços 'desertos' do mar.

Com o advento da difusão tecnológica, os homens começaram a passar por situações-limites no tocante ao exercício de provimento de seus lares. As mudanças tecnológicas no trabalho pesqueiro trouxeram consigo a ameaça real de perda dos barcos e de dificuldade financeira, visto que o pacote tecnológico deveria ser pago pela colônia através do trabalho de cada pescador. $\mathrm{O}$ que colocamos é que esta ameaça real de perda da função de provedor, por causa do endividamento com o Banco do Nordeste, pode ativar outras formas de atualização do modelo de masculinidade central. E este caminho se dá através da relação que os pescadores irão travar uns com os outros em função da posse dos aparelhos eletrônicos e do manuseio dos mesmos. Para entendermos este processo, vejamos como se dá o uso dos aparelhos e as implicações da inserção das novas tecnologias na vida dos pescadores.

De uma forma geral, os pescadores utilizaram os equipamentos de forma semelhante, apesar de haver casos de formas específicas de adesão às nova tecnologias. Esses casos foram percebidos como exemplos de 'adesão parcial a novos conhecimentos', no sentido de que nenhum deles fez uso dos equipamentos da forma prevista pelos técnicos que montaram o processo de introdução das novas tecnologias junto às comunidades. Entre os 
pescadores havia aqueles que utilizavam o GPS quando seus conhecimentos de localização no mar não podiam ser ativados (dias nublados ou chuvosos, quando não se podia visualizar à distância as marcações por terra, utilizadas tradicionalmente). Estes levavam o GPS consigo, no barco. Outros, apesar de levarem o GPS no barco, não se utilizavam deste, apenas mantinham-no consigo. Havia ainda os que, tal como seu Manuel, guardavam o GPS em casa. Esse pescador, particularmente, é um dos mais experientes da região, é mestre de pesca conhecido e respeitado por toda a comunidade devido a seu trabalho e conhecimento das marcações, dos cabeços, enfim, das técnicas tradicionais de pesca artesanal. O novo conhecimento é tomado por ele como importante, embora efetivamente ele se reconheça bastante frustrado em suas perspectivas de melhorias, que poderiam ser fruto da vinda do pacote tecnológico. Ele acredita, inclusive, que o conhecimento de novas técnicas de pesca seriam uma forma de resolução do problema de 'pouca pesca', pesca de poucos peixes. A aparelhagem eletrônica a qual ele dá o nome de 'apetrechos' não vem acrescentar melhorias e "não carece de ser compreendida e absorvida”.

Podemos entender estes casos em que os pescadores não desejam descartar os aparelhos, mesmo não fazendo uso dele no mar, como representando um espaço de status advindo de um conhecimento que é delegado a alguns e não a todos os pescadores (apenas aos que participam do projeto) e representante de poder financeiro, já que são aparelhos caros e difíceis de manusear. Aliado a isto, esses aparelhos constituem espaços de conhecimento pertencente a um mundo considerado pelas pessoas da comunidade como sendo 'moderno e avançado'.

Não há um só pescador que tenha deixado de utilizar-se da técnica artesanal de marcação por terra. Eles alegam que poderiam estar fragilizados sem a técnica antiga. Imaginemos, por exemplo, "se um desses GPS descarrega sua bateria e deixa um desses pescadores à deriva, como saber a orientação senão pelas técnicas antigas?!". Por outro lado, o GPS também pode ter uma função de grande importância quando a técnica da marcação não puder ser utilizada.

A utilização do GPS deveria trazer consigo modelos tecnológicos que auxiliariam no trabalho pesqueiro de forma mais efetiva. Ou seja, este aparelho deveria modificar a prática cotidiana de pesca, o que não aconteceu. Portanto, 
quando indagados da importância do GPS, os pescadores falam sempre que este vem preencher as lacunas da antiga técnica da marcação por terra.

Efetivamente, o que deveria acontecer para que o uso do aparelho fosse justificado, seria uma pesca que ultrapassasse os limites da plataforma continental, espaço geográfico que situa-se além dos limites da possibilidade de visualização por olho humano do continente, fator decisivo na marcação por terra. Então, outros cardumes e cabeços poderiam ser localizados e 0 GPS teria uma função 'concreta'. Na contramão desses acontecimentos, os pescadores continuam pescando apenas até os limites já conhecidos, onde o GPS não tem um sentido 'real' de utilização. O que aconteceu neste processo de intervenção dos técnicos do projeto PEditec, não nos cabe aqui discutir, colocamos, apesar disto, o dissenso entre a forma concreta de organização do conhecimento por parte dos pescadores e o novo conhecimento prático, que não se efetivou a partir das técnicas abstratas postas a seu dispor.

O encontro de expectativas e realidade concreta trouxe aos pescadores o desconforto ao tratarem de um assunto tão dúbio a seu próprio ver. Dúbio porque, de um lado, viam-se com um status adquirido através da posse de equipamentos eletrônicos 'potentes' e, muitas vezes 'complicados' para seu entendimento (caso do GPS especificamente) e sem uma necessidade que suplantasse as técnicas concretas que eles já utilizavam até então. O status adquirido pode ser visto como um ponto positivo para os pescadores que possuem esses aparelhos. Esse status pode ser visualizado por nós através da comparação entre os discursos daqueles que possuíam e dos que não possuíam os equipamentos eletrônicos na colônia.

Há um deslocamento do conceito de utilização dos instrumentos eletrônicos. Um novo espaço de conhecimento é criado aqui. Passa-se do conceito de utilidade para o de valor, status: "não uso... mas guardo com o maior cuidado em casa... (seu Fred)". "Eles tem GPS... e nós não... eu não sei mexer, não, mas já vi no barco... (seu Francisco)”.

Seu Fred possui GPS e não o utiliza. Apesar disso, mantém o mesmo bem guardado, além de levá-lo consigo para o mar algumas vezes. Enquanto isso, seu Francisco, contramestre, dono de barco, não foi ‘beneficiado' com os novos aparelhos eletrônicos e comenta sobre os mesmos com o interesse de quem vê novos incrementos e novas formas de lidar com o trabalho, e com a 
natureza que impõe saberes diferentes dos que ele possuía até então. Além disso, a inserção de novos elementos ao trabalho pesqueiro significou o aparecimento de novas relações de poder, em que quem detinha os novos equipamentos e sabia manuseá-los minimamente possuía um saber 'que era de poucos eleitos'.

Além disso, os novos equipamentos eletrônicos passam a significar espaço de status a partir do momento em que se relacionam a espaços de significação onde o saber tecnológico relaciona-se ao 'saber que vem da cidade grande'. Os valores e representações de que o conhecimento que vem das metrópoles e que os equipamentos que são eletrônicos são melhores e mais potentes, representando avanços por parte de que os possui ou manipula, formam estes espaços mentais de "manipulação do sagrado (nesse caso, sobre o GPS e a ecossonda). Entretanto, o GPS, por ser mais dificilmente manipulado, assume o protótipo deste conceito a respeito de quem detém o poder e status.

Apesar dos aparelhos não apresentarem, na prática, mudanças efetivas com relação à pesca e dos pescadores não passarem a pescar mais nem melhores peixes; aliado ao fato de que, agora deviam dinheiro ao banco por essa aparelhagem e pelo barco adquirido, estes aparelhos e os barcos mais possantes vieram ocupar esse espaço de status e poder nas relações de trabalho.

Portanto, acreditamos que os equipamentos eletrônicos, através do status ativado por sua via, vêm suprir a falta ou a impossibilidade eminente desses pescadores em continuarem provendo seus lares. Esses homens parecem estar convivendo com a mudança tecnológica de forma tal que, por um lado, deparam-se com a fragilidade financeira e a desilusão de melhor condição de vida e, por outro, encontram nos aparelhos que não são usados efetivamente, uma utilidade 'nova', que é a de resguardar seus espaços de manutenção de um modelo de masculinidade central/hegemônico, ao qual eles têm recorrido em seu mundo do trabalho.

A mudança e a efetivação do que significa para os pescadores exercerem a masculinidade se dá principalmente através do espaço do trabalho, que é onde se travam as relações dos homens uns com os outros. Mesmo que seja claro o contraponto desses homens (trabalhadores do mar) com as mulheres (as que ficam na terra), a noção de que o domínio das relações de poder e trabalho também são igualmente importantes, para pensar as implicações do gênero, ficam igualmente evidentes nesse contexto (CONNELL, 1987). 
Com relação ao status adquirido a partir da posse dos aparelhos eletrônicos, paradoxalmente, podemos dizer que os pescadores também constroem espaços de status das antigas técnicas de pesca, a partir da forma com que eles lidam com esses equipamentos eletrônicos. Ou seja, ao verem-se diante de um quadro de mudanças desfavorável economicamente, recorrem a uma exaltação das antigas técnicas de pesca como um espaço de reconhecimento e valorização do que significa ser um bom pescador. E os equipamentos eletrônicos, por conseguinte, passam a não serem utilizados efetivamente, não apenas por apresentarem dificuldades em seu trato, mas também por não serem mais tão eficazes (como os pescadores imaginavam que estes poderiam ser ao auxílio da pesca artesanal, quando entraram no projeto de difusão tecnológica) quanto às antigas técnicas da pesca.

\section{REFLEXÕES FINAIS}

Estas questões trazidas à tona por nós apontam para que não é que existam homens que queiram mudar ou que estão vivendo em condições contrárias, ou mais próximas ao modelo central de masculinidade. A idéia é a de que, muitas vezes, são os mesmos homens que estão dominados e dependentes das mulheres financeiramente ou emocionalmente, que apregoam o ideal de homem 'que manda' e se perdem em delírios de dominação do mesmo modo que o pescador que se vê ameaçado na sua condição de provedor, recorre ao que mais lhe poderia configurar como homem; frente ao outro que ameaça que tanto pode ser o tão abstrato como o concreto poder do Banco do Nordeste, quanto o pescador mais habilidoso.

Isto demonstra que as masculinidades ditas subordinadas pela literatura corrente não são versões excluídas, mas existem enquanto contidas na dita hegemonia e que a experiência é um diálogo difícil entre a 'complexidade polimorfa' dos seus sentimentos e 'o simplismo dos padrões orientadores’ (VALE DE ALMEIDA, 1996, p. 164).

Procurando manter os laços que os ligam ao modelo da masculinidade conhecida e compartilhada, esses homens buscam, frente às mudanças ocorridas em suas vidas, reorientarem-se a partir da idealização de suas 
condições de vida no passado. Mesmo que estas condições não tenham sido, na época, melhores que as atuais, eles buscam positivá-las resgatando, no caso dos pescadores, a representação de chefe de família presente nelas.

Sendo assim, apesar das diferenças existentes - homens que trabalham e homens desempregados, homens que 'sustentam mulheres'e homens que são sustentados’ - encontramos similaridades em ambas as populações no sentido de busca de idealização de um modelo que traz de volta a 'segurança de sentir-se homem'. Não se trata de afirmar, como assinalamos inicialmente, que os processos se dão da mesma forma nas duas comunidades; por esta razão insistimos em suas diferenças. A importância dessa relação está na possibilidade de pensar como mudanças na forma como as percepções e as vivências da masculinidade estão ocorrendo a partir de transformações no mundo do trabalho, um dos elementos centrais na definição de um certo modelo de "ser homem" que discutimos aqui. Aliado a isso, refletir sobre gênero a partir de relações destes homens entre si e suas hierarquias e não apenas na relação com as mulheres, condiz com o nosso propósito de refletir sobre as dinâmicas do gênero em contextos diversos.

É da observação de como esses vários níveis se cruzam que podemos pensar em que medida estamos diante de sinais de alteração desta ordem, ou se tão somente estaremos visualizando masculinidades que sempre existiram, mas que, por exatamente estarem subordinadas ao modelo, não foram percebidas ou foram vistas como desvios.

\section{REFERÊNCIAS}

ADRIÃO, Karla Galvão. No mar dos sentidos. Linguagem, cognição e construção do conhecimento em duas comunidades pesqueiras de Pernambuco. Dissertação (Mestrado em Lingüística) - CAC, UFPE, 2000.

BAKHTIN, M. Marxismo e fílosofia da linguagem. Tradução de M. lahud e Yara F Vieira. São Paulo: Hucitec, 1979. 
BARBIERI, Teresita de. Sobre la categoría género. Una introduccíon teóricometodológica. In: AZEREDO, Sandra \& STOLCKE, Verena (coords.). Direitos reprodutivos. São Paulo: FCC/DPE, 1991 p. 25-45.

BOURDIEU, P. A dominação masculina. Educação e Realidade, 20 (2): 133-84, jul/dez, 1995.

BRANDES, Stanley. Metaphors of masculinity: sex and status in adalusian folklore. University of Pensilvania Press, 2a. ed. 1985.

BRUSCHINI, C.; COSTA, Albertina O.(org.) Uma questão de gênero. Rio de Janeiro: Rosa dos Tempos, 1992.

CONNELL, Robert W. Gender and power: society, the person and sexual politics. CA: Stanford University Press, 1987.

CONNELL, Robert W. La organizacion social de la masculinidad. In: OLAVARRIA, José; VALDÉS, Teresa (eds). Masculinidades: poder y criss. Santiago, Chile: Ediciones de lãs mujeres, n. 24., 1997.

CORREAA, Sonia. Gênero e sexualidade como sistemas autônomos: idéias fora do lugar?. In: PARKER, R.; BARBOSA, R. (org.) (op. cit.) p. 149-159.

DURANTI, Alexandre. Linguistic anthropology. UK Cambridge: University Press, 1995.

FONSECA, Claudia. Aliados e rivais na familia: o conflito entre consnguineos e afins em uma vila portoalegrense. In: RBCS. 20 (2), p. 80-104, 1987.

. Uma genealogia do 'gênero'. Revista de Antropologia. Recife: Mestrado em Antropologia - UFPE, 1996. 
FRY, Peter. Da hierarquia à igualdade: a construção histórica da homossexualidade no Brasil. In: Para inglês ver. Rio de Janeiro: Zahar, p. $87-115,1982$.

FULLER, Norma. La constitución social de la identidad de género entre varones urbanos del Perú. In: Valdés, Teresa y Olavarría, José, eds. Masculinidades y equidad de género en América Latina. Santiago: FLACSO-Chile, 1998. p. 56-68.

HEILBORN, Maria Luíza. Fazendo gênero? A antropologia da mulher no Brasil. In: BRUSCHINI, C.; COSTA, A. O. (org.) (op. cit) Título. p. 93-126.

LEAL, Ondina Fachel; BOFF, Adriane de Mello. Insultos, queixas, sedução e sexualidade: fragmentos de identidade masculina em uma perspectiva relacional. In: PARKER, Richard; BARBOSA, Regina. (org.) (op. cit.) p.119-135, 1996.

MONDADA, Lorenza (1994) Verbalisation de l'espace et fabrication du savoir. Approche linguistique de la construction des objets de discours. Lausanne - Université de Lausanne, Faculte de Lettres. Thése pour obtenir lê grade de docteus em lettres (671 pp)

NASCIMENTO, Pedro Francisco Guedes do. Mulher é o Cão: A construção da identidade masculina em bar da feira central de Campina Grande - Etnografia. Departamento de Ciências sociais, UFPB, Campina Grande, 1995.

NASCIMENTO, Pedro. 1999. Ser homem ou nada: diversidade de experiências e estratégias de atualização da masculinidade hegemônica em Camaragibe. Dissertação (Mestrado) Antropologia Cultural, UFPE, Recife.

PARKER, R. G. e BARBOSA, R. M. (Orgs.). Sexualidades Brasileiras. 1. ed. Rio de Janeiro: Relume-Dumará, 1996. 
PITT-RIVERS, J. Honra e posição social. In: PERISTIANY, J. G. Honra e vergonha: valores das sociedades mediterrâneas. Lisboa: Fundação Calouste Gulbenkian, 1971.

SAFFIOTI, H. O poder do macho. São Paulo: Moderno, 1987.

SARTI, Cynthia. A família com espelho. Estudo sobre a moral dos pobres. São Paulo: Autores Associados, 1996.

SCOTT, Joan. Gênero: Uma categoria útil para análise histórica. Recife: SOS Corpo, 1993.

SCOTT, Russel P. O homem na matrifocalidade: gênero, percepção e experiências do domínio doméstico. Cadernos de Pesquisa. São Paulo, $\mathrm{N}^{0} 73$, p.38-47, maio, 1990.

VALDÉS, Teresa; OLAVARRÍA, José (eds). Masculidades: Poder e Crisis. Chile, Santiago: Ediciones de las mujeres, No 24, 1997.

VALDÉS, Teresa y OLAVARRÍA, José. Ser hombre en Santiago de Chile: a pesar de todo, un mismo modelo. In . Masculinidades y equidad de género en América Latina. Santiago: FLACSO-Chile, 1998. p. 12-35.

VALE DE ALMEIDA, Miguel. Senhores de si - Uma interpretação antropológica da masculinidade. Lisboa: Fim de Século, 1995.

.Gênero, Masculinidade e Poder: Revendo um caso do sul de Portugal. Anuário Antropológico 95. Rio de Janeiro: Tempo Brasileiro, 1996.

VIVEROS, Mara. Quebradores y cumplidores: biografias diversas de la masculinidad. In: VALDÉS, Teresa; OLAVARRÍA, José (eds.) Masculinidades y equidad de género en América Latina. Santiago: FLACSO-Chile, 1998. p. 36-55. 